\title{
Causes and Analysis of Philosophical Psychology of Sports Violence
}

\author{
Lei Zhang \\ Wuhan Textile University, Physical Education Department. \\ Wuhan City,430073,P.R.China \\ 942813917@qq.com
}

\begin{abstract}
Keywords: Sports violence; Significant features; Sports history; Philosophical anthropology
\end{abstract}
\begin{abstract}
The research method of philosophical anthropology has already formed a certain research value in the study of sports history and sports philosophy. Combating the changes in the relationship between the "spectator-participant" from the ancient Greek period, the ancient Rome-Byzantine period, and the Middle Ages, and the changes in the manifestations of sports violence that were promoted. It is found that there is historical continuity and historical sporadic history in the history of sports violence, advancing the application of philosophical anthropology in sports philosophy.
\end{abstract}

\section{Problems and Methods}

Reflections from the Definition of Sports Violence It is Generally Believed that Sports Violence refers to the Unfriendly Malicious Harm of Physical, Linguistic, and Postural Acts Performed by the Actor based on Psychological Effects in the Course of Athletic Competition. Its occurrence field is often between the audience and the athletes, both players and both audiences. Under this model of definition, sociologists have conducted more extensive discussions on the formation of sports violence in the context of social development, crowd pressure, social media, and social commercialization, and are committed to analyzing unhealthy factors in social development; Some historians regard the history of violence in sports as an entry point, and believe that sports violence shows the strong original religious color in ancient times or maps the situation of political dispute at that time. Various studies have shown the reality and historical images of sports violence, but most of them use sports violence as an example material. French sports historian GeorgeGeorges Vigarelle once pointed out profoundly that thinking about violence in sports in these ways is a study outside "sports circles" and equates universal and broad human violence with sports violence. The study of human violence in the form of a method of studying physical violence is very easy to do and it cannot be distinguished between sports violence and general physical violence. The German sociologist Norbert Elias in his book "Sports and Civilization: A Kind of Controlled Violence" defines the above definition of the way in which new definitions and methods of sports violence are newly defined. Reflection. Elias took a different approach and believed that sports is a kind of control over human physical violence and is itself a form of violence. According to Elias, sports violence is a form of violence that controls human physical violence. With the changes of political system, changes in sports rules, venues and other conditions, sports violence presents different control methods, methods and levels of violence. It can be said that Elias' description of sports violence is a product of the definition within the "sports community." Under the guidance of Elias' definition, the definition of sports violence has changed from "outside of sports" to "inside of sports", which has led to a methodological approach to study the historical development of sports violence.

Approaches to Philosophical Anthropology and the Involvement of the Audience-Participant Relationship.Because of Elias's reflection on the definition of sports violence, it is imperative to think about a method that can enter into the analysis of sports violence itself. However, the application of philosophical anthropology in sports has been a problem in contemporary domestic scholars. Made a positive attempt. The theory and method of philosophical anthropology originate from the work of Schelex and Luckmann. There is a rather lengthy and abstract analysis and reasoning. This article does not give any details, and its train of thought in 
sports research is: Do not try Exhausting all the characteristics of sports, it does not deliberately define and define the "essential attributes" of sports, but instead seeks and describes the changes of "significant" "essential" characteristics of sports in the historical process. Under the guidance of the method of philosophical anthropology, the search for distinctive features belonging to sports violence is the precursor to its analysis. Studies related to psychology and sports psychology have demonstrated the inherent "significant features" and "indispensable" conditions for the formation of sports violence, that is, sports violence results from changes in the behavior of the playing field caused by psychological changes. Mel's "frustration-attack" theory has explained this "psycho-behavioural" model of sports violence, and believes that when participants are affected by mood swings, they are prone to aggressive violence. This can explain the causes of violence between individual athletes and individuals. The psychologists Miller and Le Bon are advancing the "psychological-behavioural" model and believe that sports violence actually comes from "group psychology." It is the external environmental factors such as the audience that make the stadium setbacks and emotional fluctuations intensify and spawn. Violence. From the "frustration-attack" theory to the advancement of "population psychology" can be found.

The "community psychology" perspective explains that sports violence is a broader perspective of the "psycho-behavioural" model of sports violence, and it also covers the factors of athletes' individual and individual sports violence. The "psycho-behavioural" model needs to find specific objects at the historical level before it can be unfolded. Therefore, the "audience-participant" relationship has become a transformation of "psycho-behavioural" model from the perspective of philosophical anthropology. The "spectator-participant" relationship first appeared in the emotional beginning of the formation of sports violence. This catharsis has two directions: From the audience to the player, the audience does not passively watch the game. There is an exchange between the audience and the player's emotions and behaviors. Cries, applause, and other external actions affect each other through the athlete's skill, continuous offensive and defensive transformation, and climaxes. From the audience's shouting and cheering, athletes drew tremendous spiritual power, as if they had been given a stimulant, even under the strong emotional influence of the audience, forgotten the original tactics, showed abnormal "brave", increased the number of foul violations and infringements.Sex inhibition is weakened, so as to sow the seeds of violence. The audience gets a satisfaction from the athlete's behavior, and cheers for the athletes even more, and even achieves the situation of ecstasy. The emotion is arbitrarily pouring in, releasing in emotional release, and infecting each other, resulting in 'collective unconsciousness' from participating. From the perspective of viewers, Elias said in the article "Sports and Violence" that "the end of a sports game or the moment of victory can only bring about a momentary pleasure, only through the (time) continuation of the game, (scene) enlargement., the ups and downs of the game, and the tension of the game itself, this kind of pleasure and passion can be strengthened. The "passion and pleasure" in his article belongs to the audience level.

It is caused by the participants' competitive behaviors, which in turn can affect participants and stimulate each other to form a breeding ground for sports violence. At the emotional level, it is undoubtedly intriguing to integrate "audience-participants" with the formation of sports violence. It is possible to implement the "psychological-behavior" model of sports violence as one of "significant" and to some extent The "indispensable" feature has created research opportunities for the development of philosophy anthropology, and further the history of sports violence.

Research objects, purposes, theories, and methods of studying the ancient Greek, Roman-Byzantine, and medieval times of sports violence in the theoretical basis and methodology of philosophical anthropology, exploring the changes in the relationship between audiences and participants and the historical changes in sports violence The association between. It mainly uses the literature data method and adopts keywords such as "sports violence", "ancient Greece", "ancient Rome", "ancient Olympics", "philosophical anthropology", "gladiator", "medieval", "knight sports", etc., at the East China Normal University Library, Shanghai. China Knowledge Network, EBSCO Sports Full Text Academic Data Retrieval Platform, JSTOR Database, SAGE Database, and Persée Database were used for literature review. The period of literature was from 
1967 to 2013, with a total of 95 references and 36 references.

\section{From Ancient Greece to Middle Ages: History of "Aspect-Party" Relationship Change and Sports Violence}

The Age of Ancient Greece: The concept of differentiation between "spectators and participants" and the history of sports violence show that in ancient Greece, sports was an important social mechanism. At the same time, it also had its loftiness and secularity.In the sense of sublime, ancient Greece has a unique belief in polytheism and has formed various forms of ritual activities, covering music, drama, poetry, etc. Among them, sports competition is also an important form of worship, almost all venues and auditoriums. Are located near the place of worship. Just as the ancient Greeks founded the Olympic Games, this is a sacrifice to Zeus, the Lord of the Gods. In the worldly sense, the ancient Greek sports competition is not only the necessary training for adults on the physical level for the citizens, but also the necessary process for adults on the mental level. Through participating in and watching sports competitions, it will form a "sound spirit and a healthy body. "This idea. However, this is full of religious sacredness, adult education and secularism, and even said that full of social "positive energy" competitive sports will be accompanied by bloody sports violence, but it is worth pondering. The conceptual level differentiation between "spectator-participants" first in the ancient Greek era opened the logical and historical starting point for this reflection.From the perspective of the original concept, the concept differentiation between "audience" and "participant" is not clear. "The initial meaning of the term 'audience' is to refer to the competitor and the audience as a whole. The word 'audience' in the ancient Greek competition can be read as 'participant', 'the audience is the participant, and the participant is the audience'. If the audience is lost, then there will be no athletes participating in the competition. Therefore, there are no strict boundaries between the audience and the participants in the ancient Olympic Games. After that, the concept of differentiation was formed in the integration of the audience and the participants. The main change occurred in the first dimension of the participants and the audience was excluded from the participants: For the participants, the qualifying qualifications of the ancient Olympic Games were Obviously, only men with ancient Greek ancestry and free citizenship can participate; in the fifth century $\mathrm{AD}$, a bounty hunter who received "special food and vocational training and was away from ordinary citizens' life" was formed today. On professional athletes. The identity of the audience also began to become complex, including political officials, businessmen, celebrities, women, children, slaves, as well as inferior people and some civilians. Moreover, in order to accommodate a large number of audiences from all sides, many arena halls have a large number of auditoriums for audience use. In the ancient Greek period, numerous city-states and wars between city-states caused participants to have more obvious regional political colors and tendencies. Participants' negative and negative influences the audience greatly, such as the "Olympic Games of ancient times."Participants in the conference gradually transitioned from a pure pleasure to a competition under the influence of secular power. "The enthusiastic audience does not watch the game with purely competitive or unbiased attitude. Almost every spectator recognizes himself as an entrant - the reason for this may be the family's connection, the affiliation of the race, the identity of the country, and the hobby of the individual.' As the audience and participation form a conceptual level The differentiation and sporting violence have also received corresponding historical presentations.In the early days, the ancient Greek boxing matches had very few restrictions, but at the beginning there were only two rules: They were not allowed to catch each other's eyes and were not allowed to bite their mouths. The course of the game was rather cruel: All kinds of tricks can be used, and the opponent can be intentionally dislocated and fractured, regardless of the weight level, until one side falls or one side gives in. After the game is over, boxers are often beyond recognition. But as the identity of the participants in the competition changes, the audience The distance between the participants began to widen, and there was a more elaborate planning of competitive behavior, and the factors for pursuing violence were controlled to a certain extent.First, the participants were more of the upper class youth, so the competitive behavior was gradually educated with youth. Behavior-related, related to the cultivation of the individual's mind, related to 
the honor of the city-state; Second, the competitive behavior is more in the competitive It took place, and certain changes in the rules were formed,

Ancient Rome - The Byzantine Age. The Turning of the "Audience-Participant" Relationship Engels once said: "Without Greece, there would be no Rome, without Rome there would be no modern Europe." Therefore, the ancient Roman era had an obvious inheritance relationship with the ancient Greek era and European history. Some of the elements of ancient Greek sport have been inherited and changed in the Roman period. This brings the relationship between the "spectator-participants" of the ancient Roman era to have both Greek legacy and new forms, and the Byzantine Empire between ancient Rome and the Middle Ages fully demonstrated this transformation. At this stage, mention "Roman-Byzantine". In the "Roman-Byzantine" era, sports were first inherited..It is a religious ritualistic behavior, but the political characteristics of it have come from behind, and it has been pregnant with obvious entertainment. This point is directly reflected in the "spectator-participant" relationship of this era, changing the audience of the ancient Greek era. In the "participant" relationship, the "participants" dominated the situation and formed a reversal of the relationship between the two. The "audience" factor began to greatly influence the "participants" behavioral performance and competition methods, and caused the appearance of sports violence. Great change. One of the most characteristic features is that the gladiator movements of the Roman era and the competitive campaigns of the Byzantine era gradually replaced bloody fights. From the 11th century to the beginning of the 16th century, most of the contests were conducted only between two knights. The rules were simple and there was almost no limit, similar to a real war. For example, in 1559 Henry II was injured in the contest and died.

\section{Reflection on the Nature of Sports Violence and Research Methodology.Separating the "spectator-participant" relationship existing in sports violence with the method of philosophy and anthropology, and implementing it in the history of sports, what we hope to achieve first is to form a certain reflection on the study of sports violence, followed by the method of philosophical anthropology. Application summary and development.}

Based on the "bloody" thinking of the nature of sports violence. In many researches on sports violence, "bloody" and "bloody" are often the focus and focus of attention, and even understood as the core of sports violence. On the surface, there are certain "bloods" in different periods of sports competitions. Even in a highly civilized modern society, the "bloodiness" of sports competitions happens occasionally, even to a degree comparable to that of classical times. . And as Elias said, "The constraint on violence is not the superior nature of the 'civilized nation', not their eternal characteristics of race, but some aspects of the development of a particular society. It is a diverse but stable approach to violence. The results of social control and the corresponding conscience formation". From Elias' definition of sports violence-controlled physical violence in sports-starting with philosophical anthropology in the dimension of the change of "audience-participant" relationship, one can discover "bloodyness". It is just a manifestation of the lack of physical violence restraint factors in sports, rather than the essence of physical violence. Sports violence is more manifested as the control and restriction of physical violence by different ages and factors.

Application and Development of Philosophical Anthropology. In the study of sports philosophy, the method of philosophical anthropology has proposed new perspectives and research methods for exploring the definition of the concept of sports and the controversy over the issue of sports history. In this article, the philosophical anthropology method is used to reveal the "spectator-participant" relationship that is embedded in the appearance of sports violence. It is able to solve the misunderstanding contained in the study of sports violence and form a historical interpretation. To come can also form the promotion and development of research methods.

The historical continuity and historical contingency of sports violence. The history of sports violence is characterized by the "spectator-participant" relationship. It is different from the simple historical combing and more important is the discovery of the inevitability and contingency in history. From ancient Greece to ancient Rome to the medieval historical development, there was a 
historical process of formation and development between "audience-participants", and each stage triggered the transformation of sports violence forms. In this historical transition process, historical continuities and sporadic components are clearly highlighted:External control of physical violence-regulations, venues, restrictions on participants' identities, and internal controls - the gradual expansion of rituals, skills, and other controls is a continuation of history; while the appearance of bloodyness in sports violence is accidental. These understandings cannot be achieved through simple historical events. It also enables more direct practical value, namely the audience and the participants. The interrelated approach is a key factor in the formation of sports violence, such as changing the way the audience and the participants relate to each other, and how the participant's violence manifests itself to eliminate its bloody danger.

\section{Conclusion}

Sports violence is neither an immutable intrinsic concept nor a social phenomenon that is consistent with ancient and modern times. It is a process that occurs or is contained or degraded in different historical and social contexts. The "audience-participant" relationship Change is precisely the theoretical key to understanding the mechanism of change, and at the same time forms a new understanding of sports violence and methodological changes. Firstly, we discuss the relationship between the "audience-participant" relationship and the historical changes in sports violence in the way of philosophical anthropology.

In order to broaden and deepen the understanding of sports violence and place all the manifestations of sports violence in the context of the history of historical and cultural changes, we will investigate and eliminate the misunderstandings on shelters, and then interpret different historical and cultural backgrounds against sports violence and even sports phenomena. The valuation process; On the other hand, as a methodological attempt, the guidance of the philosophical anthropology methodology gives a vivid historical image of various abstract concepts in sports, which enables a better combination of the speculation of sports philosophy and the text of sports history. For the formation of "new knowledge," laying the foundation for a complex theory.

\section{references}

[1] Shi Yan. Attack and Violence in Competitive Sports: A Dispute in Sports PsychologyOn [J]. Journal of Tianjin Institute of Physical Education, 2003( 4) : 1 -4.

[2] Gustafson R. Human physical aggression as a function of frus-Tration: Role of aggressive cues[J]. Psychol Reports, 1986, 9 ( 5) :

$103-110$.

[3] Long Yuan. Violence in the sport of deviation from the study [J]. Anhui bodyEducation Technology, 2011( 5): 8 -11.

[4] Xu Xiang, Xie Qiuling. An Analysis of Violent Injuries in Competitive Sports_— Based on InfringementResponsibility Law Perspective [J]. Sports Research and Education, 2015(2) : 23 $-26$.

[5] Xiang Shixin. The cause of violence in sports [J]. Sports Science, 1987 ( 1) : 8 -10,94.

[6] Wang Na. The causes and analysis of sports violence [J]. Shaanxi Education: Teaching Edition,

2011( 12) : 50 - 51.

[7] Wang Yuchong, Sun Yongtai. The Cultural Representation of Early Roman Empire[J]. RiverJournal of Nanyang Institute of Education: Philosophy and Social Sciences, 2009( 1) : 78 $-81$.

[8] Han Zhifang. Gladiator: Alienation of Ancient Roman Sports [J]. Sports Culture Guide,2004( 2) : $64-65$.

[9] Jean-Jacques Courenne. The history of the body - the change of eyes: 20th centuryJi [M]. Sun Shengying, Zhao Jihong, Wu Juan, translation. Shanghai: Shanghai East China Normal University Edition, 2013: 282

[10] Elias Norbert, Dunning, Eric. Sport et Civilization: La vio-Lence Matrisée, Pairs: Fayard, 
1994.

[11] Berger P L, Luckmann T. The Social Construction of Reality[M]. New York: Anchor Books, 1967: 8 .

[12] Gao Qiang. Between the "grey" philosophical theory and "evergreen" sports:The introduction of philosophical anthropology in academic research [J]. Sports and Science, 2013, 34( 11) : 32 $-36$.

[13] Gao Qiang. Sports and the City: A Study of Philosophical Anthropology [J]. Sports Section Learning, 2014, 34(1).

[14] Guo Xiaofei. A review of the main infringement theories in the West [J]. Shaoxing University of Arts and SciencesJournal of: Philosophy and Social Sciences, 2000( 1) : 86 -90.

[15] Cai Li. Criminal Psychological Causes Summary [J]. Social Psychological Science, 2007 (Z3):124 - 127.

[16] Chen Nana, Wei Honghao. Psychological analysis of sports violence causes [J]. Anhui Sports Technology, 2010( 2): 64 -67.

[17] Liu Lina. On setbacks and violations [J]. Social Psychological Science, 1998,( 1) : 52 -56. 